\title{
Real-world efficacy and safety of insulin degludec with mealtime rapid-acting insulin in type 1 diabetes in Indian pediatric population
}

Inderpal Singh Kochar ${ }^{*}$ (D) and Aashish Sethi

\begin{abstract}
Background: Insulin Degludec (IDeg) is a new ultra-long-acting basal insulin that has not been yet evaluated in Indian pediatric population. We aim to evaluate the efficacy and safety of IDeg as basal-bolus therapy in Indian pediatric patients affected by type 1 diabetes mellitus (T1DM).

Methods: A total of 30 pediatric and adolescent patients (17 boys, 13 girls; 22 were pre-pubertal) with T1DM who were on IDeg once daily participated in the study. All the patients received IDeg for at least 26 weeks along with rapid-acting mealtime insulin and their pre- and post-baseline characteristics (anthropometric data (BMI), age, duration of diabetes), metabolic ( $\mathrm{HbA1C}$ ), insulin requirement (unit/kg body weight per day) and number of hypoglycemia episodes were recorded along with the daily self-monitoring of blood glucose.
\end{abstract}

Results: There was a significant decline in $\mathrm{HbA1c}, \mathrm{FPG}$ and bolus insulin dose from baseline to 26 weeks in the overall population (HbA1c: $9.65 \pm 1.998 \%$ to $8.60 \pm 1.631 \%, P=0.0014$; FPG: $156.93 \pm 42.373 \mathrm{mg} / \mathrm{dL}$ to $109.37 \pm 28.531 \mathrm{mg} / \mathrm{dL}$, $P=0.000004$; bolus insulin dose: $0.49 \pm 0.208 \mathrm{U} / \mathrm{kg} /$ day to $0.35 \pm 0.155 \mathrm{U} / \mathrm{kg} /$ day, $P=0.00032$ ). The basal insulin dose was significantly higher at 26 weeks compared to baseline dose $(0.42 \pm 0.134 \mathrm{U} / \mathrm{kg} /$ day to $0.46 \pm 0.139 \mathrm{U} / \mathrm{kg} /$ day, $P=0.04219)$. There was no significant change in BMl at 26 weeks.

None of the patients experienced any DKA episode for 26 weeks. 16.7\% patients had experienced at least one symptomatic hypoglycemia episode. On CGMS among the patients who were shifted from Glargine to degludec hypoglycemia were reduced significantly (overall hypoglycemia: $1.92 \pm 1.26$ to $0.35 \pm 0.49$ episodes over 3 days, $P=0.0026$ while nocturnal hypoglycemia: $0.92 \pm 0.47$ to $0.21 \pm 0.42$ episodes, $P=0.0021$ ). None of the patients had severe hypoglycemia episode.

Conclusion: In our study IDeg is found to be safe and effective long-acting basal insulin that can be used in Indian pediatric population with T1DM. However further long term prospective studies are required to evaluate the long term effects.

Keywords: Adolescents, Children, Hypoglycemia, Insulin Degludec, Type 1 diabetes

\footnotetext{
*Correspondence: inderpal_kochar@yahoo.com

Indraprastha Apollo Hospital, New Delhi, India
}

(c) The Author(s). 2018 Open Access This article is distributed under the terms of the Creative Commons Attribution 4.0 International License (http://creativecommons.org/licenses/by/4.0/), which permits unrestricted use, distribution, and reproduction in any medium, provided you give appropriate credit to the original author(s) and the source, provide a link to the Creative Commons license, and indicate if changes were made. The Creative Commons Public Domain Dedication waiver (http://creativecommons.org/publicdomain/zero/1.0/) applies to the data made available in this article, unless otherwise stated. 


\section{Background}

Type 1 diabetes mellitus (T1DM), is one of the most common pediatric endocrine illnesses [1]. Globally, 78,000 children under 15 years of age are estimated to develop T1DM annually. Recent reports have estimated that 24 and $23 \%$ of pediatric diabetic patients belong to European and South-East Asian regions, respectively [2]. India alone is a home of around 97,700 children with T1DM [1].

T1DM management in children and adolescents is a challenging task due to their pubertal or hormonal changes, variable daily schedules, flexible and irregular meal timings, fear of needles, correct injection-site rotation and/or subcutaneous injection depths, pain during injections, social stigma and varying family support [3]. The complex interaction between these trajectories has shown limited success of medical or psychological interventions so far [4]. Hypoglycemia, particularly nocturnal hypoglycemia, is considered as the major barrier in achieving glycemic control [5]. Long-term sequelae of hypoglycemic episodes may impair neuropsychological functioning and decrease quality of life [6]. This fear of hypoglycemia frequently results in insufficient insulin supplementation, which may lead to hyperglycemia and diabetic ketoacidosis (DKA) [7]. Various studies have shown that reduced cognitive ability was more closely related to the presence of microangiopathy, suggesting that chronic hyperglycemia has a greater adverse impact on the brain [8]. The Clinical Practice Consensus Guideline recommends optimal glycemic control without severe hypoglycemia to be the main target in T1DM management in children and adolescents [9].

Basal-bolus insulin therapy plays a pivotal role in lowering the glycemic level where long-acting basal insulin analogues have long duration of action, low nocturnal hypoglycemic risk and less variability. However, they only lasts for $24 \mathrm{~h}$ and start decreasing at the end hours, thereby leading to occasional hyperglycemia just before the next insulin dose \& requiring next dose to be given at fixed time of the day [10]. Hence, insulin Degludec (IDeg), an ultra-long-acting basal analog approved by the US Food and Drug Administration (FDA) on September 25, 2015 was developed with the properties of having a flat peakless profile, less day-to-day variability, once-daily dosing, flexible timing of administration, long-acting profile $(>42 \mathrm{~h})$, low overall and nocturnal hypoglycemia, a mean elimination half-life of $\sim 25 \mathrm{~h}$ and an ability to mix with other insulins. On subcutaneous injection, it self-associates and forms a depot of soluble multihexamers that further allows a stable and slow release of monomers into the circulation [11].

A battery of literature supports the effective and safe use of IDeg over other basal insulin analogs in T1DM adult population in terms of significant glycemic control with a lower risk of hypoglycemia, nocturnal hypoglycemia, dose requirement and higher flexibility [12-14]. However, only few IDeg studies have been reported in children and adolescents with T1DM. The efficacy and safety of IDeg have not been evaluated in Indian pediatric population with T1DM. Hence, the present study was undertaken to assess the real-world efficacy and safety of IDeg in basal-bolus treatment, with mealtime rapid-acting insulin, in Indian pediatric T1DM patients.

\section{Methods \\ Study design}

This was a 26-week, non-randomized, open-label study involving retrospective data collection from 30 children and adolescents with T1DM. All the patients attended the pediatric outpatient department of the Indraprastha Apollo hospital, Delhi between February 2016 to February 2017. The study enrolled T1DM patients who were on treatment with Long acting Insulin degludec along with rapid acting mealtime insulin (Aspart/Lispro/Glulisine) for at least 26 weeks and maintained blood glucose diary with atleast 3 point SMBG daily, and have continuous glucose monitoring system (CGMS) data using Medtronic iPro2 Professional CGM (at time of switching from insulin Glargine to degludec). The study was initiated after taking an approval from institutional ethics committee and was conducted in accordance with principals of the Declaration of Helsinki and ICH Good Clinical Practice.

The anthropometric data [body mass index, height, weight, Standard Deviation Score(SDS) as per standard growth charts (<5 years-WHO, 5-18 years-IAP 2015 Growth curves)], age, HbA1c, basal and bolus insulin requirement (unit/kg bodyweight/day), SMBG data from diabetic diary (Fasting sugar taken as average of 7 days fasting glucose reading) and the safety variables were recorded into the paper case record form at baseline and 26 weeks' post-baseline. The safety variables included episodes of hypoglycemia [self-measured plasma glucose level $<70 \mathrm{mg} / \mathrm{dL}$, regardless of symptoms, by collecting data from self-maintained Blood Glucose diary, hypoglycemia recorded on CGMS iPro2 (for 3 days at shifting from Glargine to degludec and after 26 weeks)], hyperglycemia (prandial glucose levels $>200 \mathrm{mg} / \mathrm{dL}$ ) and DKA, lipodystrophy, local site reactions and any other adverse events (AEs). The data entry was further validated and analyzed statistically.

\section{Study endpoints}

The primary endpoint of the study was change in HbA1c level from baseline to 26 weeks. The secondary endpoints were changes in BMI, insulin dose (bolus, basal and total) and mean FPG levels from baseline to 26 weeks. The safety parameters were also evaluated 
during the study. The exploratory endpoint was to assess the changes in HbA1c, BMI, insulin dose and FPG from baseline to 26 weeks by gender, age (1-6 years, 612 years and $>12$ years) and comparison from previous basal insulin.

\section{Statistical analyses}

The descriptive statistics for continuous variables like HbA1c, BMI, FPG was presented with number $(\mathrm{N})$ of non-missing observations, mean, standard deviation, median, minimum and maximum (range). For categorical data, descriptive statistics was presented with a number $(\mathrm{N}$ or $\mathrm{n})$ and their percentages. All the statistical tests were done at $5 \%$ level of significance.

Changes from baseline to week 26 for HbA1c, BMI, FPG and insulin dose were analyzed using paired t-test to test if there was a significant difference between baseline and week 26. Paired t-test was also applied individually on 3 age groups and gender. The t-test was used to test significant difference between age groups and males and females.

\section{Results}

Out of 189 Type 1 Diabetes patients who were on basal-bolus insulin therapy with insulin degludec, $30 \mathrm{pa}-$ tients matched the inclusion criteria, 17 were males and 13 were females. 20 patients (Duration of diabetes 3.09 \pm 2.61 years) were shifted from Glargine to insulin degludec (Group A) (Basal insulin decreased by $10 \%$ while bolus insulin kept as same) and 10 patients were insulin naïve patients (Group B) in whom basal characteristics (BMI, HbA1c, FPG, basal and bolus insulin doses) were retrospectively collected at 1 month after diagnosis. Baseline characteristics of the overall population and by stratified age groups are summarized in Table 1. The comparison of BMI, HbA1c, FPG, basal and bolus insulin doses at baseline and 26 weeks post IDeg treatment in the overall population, both and by age groups ( $1-6$ years, $6-12$ years and $>12$ years), gender \& in both groups is shown in Table 2, Table 3 and Table 4 respectively. The comparison of hypoglycemic episodes recorded in CGMS shown in Table 5.

\section{Comparison of BMI at 26 weeks after treatment}

There was no significant change in BMI SDS from baseline to 26 weeks in the overall population and no changes in both groups. Similar results were reported when BMI data was compared by age groups. In addition, no significant difference in BMI at 26 weeks from baseline was reported between patients of different age groups.

\section{Comparison of glycemic levels ( $\mathrm{HbA} 1 \mathrm{c}$ and FPG) at 26 weeks after treatment}

There was a significant decline in HbA1c and FPG levels from baseline to 26 weeks in the overall population (HbA1c: $9.65 \pm 1.998 \%$ to $8.60 \pm 1.631 \%, P=0.0014$; FPG: $156.93 \pm$ $42.373 \mathrm{mg} / \mathrm{dL}$ to $109.37 \pm 28.531 \mathrm{mg} / \mathrm{dL}, P=0.000004)$.

There was a significant decline in HbA1c and FPG levels from baseline to 26 weeks in both groups (Group A HbA1C difference: $0.33 \pm 0.52, P=0.010$ \& FPG difference: $31.30 \pm 22.21, P<0.001$ while Group B HbA1C difference: $2.47 \pm 2.13, P=0.005$ \& FPG difference: $80.10 \pm$ $62.58, P=0.003)$.

Table 1 Baseline Characteristics

\begin{tabular}{|c|c|c|c|c|}
\hline \multirow[t]{2}{*}{ Characteristics } & \multirow{2}{*}{$\begin{array}{l}\text { Total } \\
\text { Population }\end{array}$} & \multicolumn{3}{|l|}{ Age categories } \\
\hline & & $1-6$ years & $6-12$ years & $>12$ years \\
\hline Number of Patients & 30 & 8 & 14 & 8 \\
\hline Female/Male & $13 / 17$ & $2 / 6$ & $6 / 8$ & $5 / 3$ \\
\hline Age (years) & $9.23 \pm 3.942$ & $4.54 \pm 0.962$ & $9.07 \pm 1.619$ & $14.22 \pm 2.229$ \\
\hline Weight (kg) & $30.11 \pm 13.161$ & $18.11 \pm 4.209$ & $29.10 \pm 10.627$ & $43.88 \pm 10.346$ \\
\hline Weight (SDS) & $-0.15 \pm 1.41$ & $0.27 \pm 1.35$ & $-0.06 \pm 1.00$ & $-0.59 \pm 0.78$ \\
\hline Height (cm) & $130.09 \pm 18.906$ & $108.19 \pm 9.494$ & $130.14 \pm 11.374$ & $151.89 \pm 7.691$ \\
\hline Height (SDS) & $-0.04 \pm 1.13$ & $0.39 \pm 1.56$ & $-0.27 \pm 1.39$ & $-0.54 \pm 1.15$ \\
\hline BMI $\left(\mathrm{kg} / \mathrm{m}^{2}\right)$ & $16.99 \pm 3.364$ & $15.28 \pm 1.274$ & $16.79 \pm 3.297$ & $19.04 \pm 4.108$ \\
\hline BMI (SDS) & $0.04 \pm 0.97$ & $0.04 \pm 0.81$ & $0.10 \pm 0.91$ & $-0.43 \pm 0.89$ \\
\hline $\mathrm{HbA1c}(\%)$ & $9.65 \pm 1.998$ & $8.59 \pm 0.753$ & $10.32 \pm 2.213$ & $9.53 \pm 2.159$ \\
\hline FPG (mg/dL) & $156.93 \pm 42.373$ & $136.50 \pm 12.862$ & $176.43 \pm 49.781$ & $143.25 \pm 34.919$ \\
\hline \multicolumn{5}{|c|}{ Insulin dose (U/kg of body weight/day) } \\
\hline Basal insulin & $0.42 \pm 0.134$ & $0.38 \pm 0.120$ & $0.46 \pm 0.165$ & $0.40 \pm 0.069$ \\
\hline Bolus dose & $0.49 \pm 0.208$ & $0.37 \pm 0.115$ & $0.57 \pm 0.255$ & $0.48 \pm 0.128$ \\
\hline
\end{tabular}

$B M I$ body mass index, FPG fasting plasma glucose, HbAlc glycated hemoglobin, SDS Standard Deviation Score 
Table 2 Comparison of BMI, HbA1c, FPG, Basal and Bolus Insulin Doses at Baseline and 26 weeks after IDeg Treatment by Age

\begin{tabular}{|c|c|c|}
\hline Characteristics & Baseline & 26 weeks \\
\hline \multicolumn{3}{|l|}{ BMI $\left(\mathrm{kg} / \mathrm{m}^{2}\right)(\mathrm{SDS})$} \\
\hline Overall population $(N=30)$ & $16.99 \pm 3.364(0.04 \pm 0.97)$ & $17.39 \pm 3.005(0.15 \pm 0.89)$ \\
\hline $1-6$ years $(n=8)$ & $15.28 \pm 1.274(0.04 \pm 0.81)$ & $15.83 \pm 1.199(0.48 \pm 0.63)$ \\
\hline $6-12$ years $(n=14)$ & $16.79 \pm 3.297(0.10 \pm 0.91)$ & $17.18 \pm 2.653(0.20 \pm 0.91)$ \\
\hline$>12$ years $(n=8)$ & $19.04 \pm 4.108(-0.16 \pm 1.11)$ & $19.33 \pm 3.964(-0.15 \pm 1.06)$ \\
\hline \multicolumn{3}{|l|}{$\mathrm{HbA1c}(\%)$} \\
\hline Overall population $(\mathrm{N}=30)$ & $9.65 \pm 1.998$ & $8.60 \pm 1.631^{*}$ \\
\hline $1-6$ years $(n=8)$ & $8.59 \pm 0.753$ & $8.31 \pm 0.930$ \\
\hline $6-12$ years $(n=14)$ & $10.32 \pm 2.213$ & $8.50 \pm 1.024^{* \#}$ \\
\hline$>12$ years $(n=8)$ & $9.53 \pm 2.159$ & $9.06 \pm 2.802$ \\
\hline \multicolumn{3}{|l|}{$\mathrm{FPG}(\mathrm{mg} / \mathrm{dL})$} \\
\hline Overall population $(\mathrm{N}=30)$ & $156.93 \pm 42.373$ & $109.37 \pm 28.531^{*}$ \\
\hline $1-6$ years $(n=8)$ & $136.50 \pm 12.862$ & $105.75 \pm 26.114^{*}$ \\
\hline $6-12$ years $(n=14)$ & $176.43 \pm 49.781$ & $108.36 \pm 28.678^{*}$ \\
\hline$>12$ years $(n=8)$ & $143.25 \pm 34.919$ & $114.75 \pm 33.363^{*}$ \\
\hline \multicolumn{3}{|c|}{ Insulin dose (U/kg of body weight/day) } \\
\hline \multicolumn{3}{|l|}{ Basal insulin } \\
\hline Overall population $(N=30)$ & $0.42 \pm 0.134$ & $0.46 \pm 0.139^{*}$ \\
\hline $1-6$ years $(n=8)$ & $0.38 \pm 0.120$ & $0.41 \pm 0.109$ \\
\hline $6-12$ years $(n=14)$ & $0.46 \pm 0.165$ & $0.52 \pm 0.163$ \\
\hline$>12$ years $(n=8)$ & $0.40 \pm 0.069$ & $0.41 \pm 0.074$ \\
\hline \multicolumn{3}{|l|}{ Bolus insulin } \\
\hline Overall population $(\mathrm{N}=30)$ & $0.49 \pm 0.208$ & $0.35 \pm 0.155^{*}$ \\
\hline $1-6$ years $(n=8)$ & $0.37 \pm 0.115$ & $0.27 \pm 0.077^{*}$ \\
\hline $6-12$ years $(n=14)$ & $0.57 \pm 0.255$ & $0.39 \pm 0.176^{*}$ \\
\hline$>12$ years $(n=8)$ & $0.48 \pm 0.128$ & $0.37 \pm 0.156^{*}$ \\
\hline
\end{tabular}

$B M I$ body mass index, FPG fasting plasma glucose, HbA1c glycated hemoglobin, SDS Standard Deviation Score

${ }^{*} P<0.05$ versus baseline (paired $\mathrm{t}$-test)

$\# P<0.05$ versus $1-6$ years (t-test)

The HbA1c levels declined at 26 weeks from baseline in all the 3 age groups. However, this decline was only significant in the age group $6-12$ years $(10.32 \pm 2.213 \%$ to $8.50 \pm$ $1.024 \%, P=0.0035)$. Between different age groups, the HbA1c decline was significantly higher in 6-12 year category compared to 1-6 year category (HbA1c difference: $-1.82 \pm 1.918 \%$ versus $-0.28 \pm 0.417 \%, P=0.0375$ ). There was no significant difference between other age categories.

Regarding FPG levels, there was a significant decline from baseline to 26 weeks in all the 3 age categories but no significant difference in the FPG level was reported between the age groups.

\section{Comparison of basal and bolus insulin doses at 26 weeks after treatment}

The basal insulin dose (unit of insulin $/ \mathrm{kg}$ of body weight/day) was significantly higher and bolus insulin dose was significantly lower at 26 weeks compared to doses at baseline in the overall population (basal insulin dose: $0.42 \pm 0.134 \mathrm{U} / \mathrm{kg} /$ day to $0.46 \pm 0.139 \mathrm{U} / \mathrm{kg} /$ day, $P$ $=0.04219$; bolus insulin dose: $0.49 \pm 0.208 \mathrm{U} / \mathrm{kg} /$ day to $0.35 \pm 0.155 \mathrm{U} / \mathrm{kg} /$ day, $P=0.00032$ ).

There was increase in Basal insulin in both groups (A\&B) (Group A Basal insulin difference: $0.02 \pm 0.08 \mathrm{U} / \mathrm{kg} /$ day \& Group B Basal insulin difference: $0.06 \pm 0.11 \mathrm{U} / \mathrm{kg} /$ day) while it was not statistically significant. A decrease in bolus insulin in both groups (A\&B) (Group A bolus insulin difference $0.14 \pm 0.13 \mathrm{U} / \mathrm{kg} /$ day, $P<0.001$, Group $B$ bolus insulin $0.13 \pm 0.27 \mathrm{U} / \mathrm{kg} /$ day, $P=0.160$ ), and it was significant in patients who were previously on insulin Glargine (Group A).

There was an increase in basal insulin dose from baseline to 26 weeks in all the 3 age groups, but this change was not significant in either of the age groups. A significant decrease in bolus insulin dose at 26 weeks from baseline was reported across all the age groups. The 
Table 3 Comparison of BMI, HbA1c, FPG, Basal and Bolus Insulin Doses at Baseline and 26 weeks after IDeg Treatment by Gender

\begin{tabular}{|c|c|c|}
\hline Characteristics & Baseline & 26 weeks \\
\hline \multicolumn{3}{|l|}{$\mathrm{BMI}\left(\mathrm{kg} / \mathrm{m}^{2}\right)(\mathrm{SDS})$} \\
\hline Female $(n=13)$ & $17.73 \pm 3.897(0.07 \pm 0.97)$ & $18.07 \pm 3.882(0.20 \pm 0.82)$ \\
\hline Male $(n=17)$ & $16.42 \pm 2.885(-0.02 \pm 0.93)$ & $16.87 \pm 2.099(0.16 \pm 0.88)$ \\
\hline \multicolumn{3}{|l|}{$\mathrm{HbA1c}(\%)$} \\
\hline Female $(n=13)$ & $9.35 \pm 1.824$ & $8.37 \pm 0.772^{*}$ \\
\hline Male $(n=17)$ & $9.88 \pm 2.147$ & $8.78 \pm 2.074^{*}$ \\
\hline \multicolumn{3}{|l|}{$\mathrm{FPG}(\mathrm{mg} / \mathrm{dL})$} \\
\hline Female $(n=13)$ & $157.77 \pm 54.259$ & $108.85 \pm 25.980^{*}$ \\
\hline Male $(n=17)$ & $156.29 \pm 32.330$ & $109.76 \pm 31.126^{*}$ \\
\hline \multicolumn{3}{|c|}{ Insulin dose (U/kg of body weight/day) } \\
\hline \multicolumn{3}{|l|}{ Basal insulin } \\
\hline Female $(n=13)$ & $0.45 \pm 0.115$ & $0.49 \pm 0.136$ \\
\hline Male $(n=17)$ & $0.41 \pm 0.148$ & $0.44 \pm 0.141^{*}$ \\
\hline \multicolumn{3}{|l|}{ Bolus insulin } \\
\hline Female $(n=13)$ & $0.57 \pm 0.212$ & $0.43 \pm 0.161^{*}$ \\
\hline Male $(n=17)$ & $0.44 \pm 0.193$ & $0.29 \pm 0.122^{*}$ \\
\hline
\end{tabular}

$B M I$ body mass index, FPG fasting plasma glucose, HbA1c glycated hemoglobin, SDS Standard Deviation Score

${ }^{*} P<0.05$ versus baseline (paired $\mathrm{t}$-test)

Table 4 Comparison of BMI, HbA1c, FPG, Basal and Bolus Insulin Doses at Baseline and 26 weeks after IDeg Treatment among patients who were previously on insulin Glargine (Group A) vs. previously insulin naïve (Group B)

\begin{tabular}{|c|c|c|}
\hline Characteristics & Baseline & 26 weeks \\
\hline \multicolumn{3}{|l|}{ BMI (SDS) } \\
\hline Group A $(n=20)$ & $-0.11 \pm 0.76$ & $0.04 \pm 0.73$ \\
\hline Group B $(n=10)$ & $0.38 \pm 1.31$ & $0.37 \pm 1.19$ \\
\hline \multicolumn{3}{|l|}{$\mathrm{HbA} 1 \mathrm{c}(\%)$} \\
\hline Group A $(n=20)$ & $8.50 \pm 0.65$ & $8.16 \pm 0.67^{*}$ \\
\hline Group B $(n=10)$ & $11.94 \pm 1.78$ & $9.47 \pm 2.52^{*}$ \\
\hline \multicolumn{3}{|l|}{$\mathrm{FPG}(\mathrm{mg} / \mathrm{dL})$} \\
\hline Group A $(n=20)$ & $135.80 \pm 19.05$ & $104.50 \pm 20.69^{*}$ \\
\hline Group B $(n=10)$ & $199.20 \pm 45.18$ & $119.10 \pm 39.50^{*}$ \\
\hline \multicolumn{3}{|c|}{ Insulin dose (U/kg of body weight/day) } \\
\hline \multicolumn{3}{|l|}{ Basal insulin } \\
\hline Group A $(n=20)$ & $0.45 \pm 0.15$ & $0.47 \pm 0.14$ \\
\hline Group B $(n=10)$ & $0.36 \pm 0.05$ & $0.43 \pm 0.13$ \\
\hline \multicolumn{3}{|l|}{ Bolus insulin } \\
\hline Group A $(n=20)$ & $0.46 \pm 0.20$ & $0.32 \pm 0.10^{*}$ \\
\hline Group B $(n=10)$ & $0.54 \pm 0.22$ & $0.41 \pm 0.21$ \\
\hline \multicolumn{3}{|l|}{ Total insulin } \\
\hline Group A $(n=20)$ & $0.91 \pm 0.33$ & $0.79 \pm 0.21^{*}$ \\
\hline Group B $(n=10)$ & $0.91 \pm 0.24$ & $0.84 \pm 0.31$ \\
\hline
\end{tabular}

$\mathrm{BMI}=$ body mass index; $\mathrm{FPG}=$ fasting plasma glucose; $\mathrm{HbA} 1 \mathrm{c}=$ glycated hemoglobin, $\mathrm{SDS}=$ Standard Deviation Score

${ }^{*} P<0.05$ versus baseline (paired t-test) difference in basal and bolus insulin doses at 26 weeks from baseline was not significant between the age groups.

\section{Comparison of BMI, HbA1c, FPG, basal and bolus insulin doses at 26 weeks after treatment within and between} males and females

There was a significant decline in HbA1c and FPG levels and bolus insulin dose from baseline to 26 weeks in both genders. The basal insulin dose increased from baseline to 26 weeks in both genders, but the increase was significant only in males. No significant change in BMI from baseline to 26 weeks was reported in both genders (Table 3).

There was no significant difference in average BMI, HbA1c, FPG, basal and bolus insulin doses at 26 weeks post IDeg treatment between males and females.

\section{Safety parameters}

Five (16.7\%) and 13 (43.3\%) patients had experienced at least one symptomatic hypoglycemia and hyperglycemic

Table 5 Comparisons of the frequencies of overall and nocturnal hypoglycemia ( $\mathrm{glucose}<70 \mathrm{mg} / \mathrm{dl}$ ) events recorded on CGMS over 3 days when using Insulin Glargine and Insulin Degludec

\begin{tabular}{lllll}
\hline & & 0 weeks & 26 weeks & $P$ \\
\hline 1 & Total Hypoglycemia & $1.92 \pm 1.26$ & $0.35 \pm 0.49$ & $0.0026^{*}$ \\
2 & Nocturnal Hypoglycemia & $0.92 \pm 0.47$ & $0.21 \pm 0.42$ & $0.0021^{*}$ \\
\hline${ }^{* P}<0.05$ versus baseline (paired t-test) & &
\end{tabular}


episodes, respectively. One (3.33\%) patient had lipodystrophy who was on insulin treatment for past 5 years and $3(10 \%)$ patients had local site reactions. No other AEs were reported in the study. None of the patients experienced any severe hyperglycemia episodes, and DKA episodes after IDeg treatment.

Nocturnal hypoglycemia was only observed during the continuous glucose monitoring system (CGMS) using Medtronic iPro2 Professional CGM among the patients who were previously on glargine, which was done for 3 days period just before starting of IDeg and after 26 weeks (Table 5); which showed significant reduction in nocturnal hypoglycemia (overall hypoglycemia: $1.92 \pm 1.26$ to $0.35 \pm 0.49$ episodes over 3 days, $p=0.0026$ while nocturnal hypoglycemia: $0.92 \pm 0.47$ to $0.21 \pm 0.42, p=0.0021)$.

\section{Discussion}

The present observational study aims to evaluate efficacy and safety of IDeg, a long-acting basal insulin, along with mealtime rapid-acting insulin for 26 weeks in children and adolescents with T1DM during their routine clinical care. During the study, T1DM patients showed a significant decline in their glycemic levels and daily bolus insulin doses at 26 weeks.

Severe and recurrent episodes of hypoglycemia in young children and adolescents may result in poor neurocognitive outcomes [8]. Hence, avoidance of hypoglycemic episodes in this age group should be given a major consideration. To maintain optimal glycemic control and a target $\mathrm{HbA} 1 \mathrm{c}$ of $<7.5 \%$, as suggested by The International Society for Pediatrics and Adolescent Diabetes (ISPAD), without associated hypoglycemic episodes is considered as one of the biggest challenges in children and adolescents. In our study, there was a significant increase in basal insulin dose $/ \mathrm{kg}$ of body weight/ day requirement at week 26 than at baseline, however this was not significant individually in the groups. However, another study evaluating efficacy and safety of IDeg in children and adolescents with T1DM reported a significant reduction in basal insulin dose from baseline to 6 months $(21.8 \pm 8.9 \mathrm{IU} /$ day vs. $19.4 \pm 7.8 \mathrm{IU} /$ day, $P=$ 0.003) [15]. Thalange and co-workers have also observed reduction in the mean daily basal insulin dose in IDeg group compared to IDet group at week $52(0.38 \mathrm{U} / \mathrm{kg}$ versus $0.55 \mathrm{U} / \mathrm{kg}$ ), though the difference did not reach statistical significance [16]. Similar results were observed when the daily IDeg dose at week 24 was compared to the baseline dose [17].

In our study, we report a significant decrease in bolus insulin dose from baseline to week 26. Similar results have been reported in the previous study, indicating a significant reduction in bolus insulin dose from baseline to 6 months $(0.56 \pm 0.13$ to $0.50 \pm 0.15 \mathrm{U} / \mathrm{kg} /$ day;
$P=0.02)$ [18]. However, no significant changes in bolus insulin dose from baseline was reported in other studies [16, 17].

Thalange et al. reported equivalent HbA1c level with significant reduction in FPG with IDeg when compared to IDet [16]. In another study, there was no significant improvement in HbA1c but a significant decline in FPG was evident after 6 months of IDeg treatment [15]. The present study depicts significant reduction in HbA1C and FPG in overall population and among groups containing patients who were shifted from Glargine and insulin naïve patients.

The ISPAD recommends HbA1c $<7.5 \%$ as the target glycemic level in children and adolescents with T1DM, regardless of age [7]. Basal bolus regimens, with IDeg as a basal insulin, helps in achieving optimal glycemic controls with minimal or no episodes of hypoglycemia. Various studies have reported low frequency of nocturnal hypoglycemia and non-inferiority of IDeg with IGlar in terms of glycemic levels (HbA1c and FPG) in adult T1DM patients $[16,17]$. This reduction in hypoglycemia with IDeg is probably due to lower day-to-day and within-day variability and stable glucose lowering effect, which might facilitate titration and enable strict glycemic control [19]. In our study, significant reduction in hypoglycemia (overall and nocturnal) was observed on CGMS among patients shifted from Glargine to degludec.

Besides being effective, IDeg was found to be safe in Indian pediatric population aged $<18$ years. Only 5 of 30 patients had symptomatic hypoglycemia and there was significantly decreased number of nocturnal hypoglycemia. Our results were in parallel to the reported literature where IDeg was associated with numerically or significantly lower rates of nocturnal hypoglycemia in children and adolescents with T1DM $[16,17]$. The reduced association of IDeg with nocturnal hypoglycemia, irrespective of patient's age, was due to its lower pharmacodynamic variability during nighttime [18]. No episode of DKA was reported during the 26 weeks of the study while if look at the data among the patients who were previously on insulin Glargine; no episodes of DKA was found in past 6 months while patient were on glargine.

The study has few limitations. First, it was a single-arm and a non-controlled observational study, involving retrospective data collection. Second, the sample size was small for evaluating efficacy and safety of IDeg in children and adolescents. Third, it was a single center study, imposing centre-based biased results. Fourth, it was a short duration study, which limited viability of the data.

\section{Conclusion}

IDeg treatment in Indian children and adolescents with T1DM results in significant glycemic control with 
reduced hypoglycemic episodes and bolus insulin doses over the period of 26 weeks. Reduction in nocturnal hypoglycemic episodes has been reported in the study. However further long term prospective studies are required to evaluate the long-term effects.

\section{Funding}

This is a self-supported work. There were no funds received from any organization regarding this study.

\section{Availability of data and materials}

Raw Data in the form of excel sheet is submitted along with the manuscript.

\section{Authors' contributions}

IPS has conceptualized the idea of this study. IPS and AS both have contributed equally in study design, data collection, statistical analysis and drafting of manuscript. Both authors read and approved the final manuscript.

\section{Ethics approval and consent to participate}

The study was initiated after taking an approval from institutional ethics committee (Apollo Hospital, Delhi) and was conducted in accordance with principals of the Declaration of Helsinki and ICH Good Clinical Practice. Informed written Consent was taken from Parents before enrolling the child in study.

Clinical Study Reference Application Number: |AH/076/02-17

Name of Ethics Committee: Institutional Ethics Committee-Clinical Studies, Indraprastha Apollo Hospital, New Delhi, India

Ethics Committee Registration Number : ECR/5/Inst/DI/2013

Date of Approval: 3rd March, 2017

\section{Consent for publication}

This article does not include any individual participant's data in any form. Informed written consent was taken from Parents before enrolling the child in study.

\section{Competing interests}

The authors declare that they have no competing interests.

\section{Publisher's Note}

Springer Nature remains neutral with regard to jurisdictional claims in published maps and institutional affiliations.

Received: 31 January 2018 Accepted: 9 July 2018

Published online: 27 July 2018

\section{References}

1. Kumar KM. Incidence trends for childhood type 1 diabetes in India. Indian J Endocrinol Metab. 2015;19:S34-5.

2. Das AK. Type 1 diabetes in India: overall insights. Indian J Endocrinol Metab. 2015;19:S31-S3.

3. Kakleas K, Kandyla B, Karayianni C, Karavanaki K. Psychosocial problems in adolescents with type 1 diabetes mellitus. Diabetes Metab. 2009;35:339-50

4. Eilander MM, de Wit M, Rotteveel J, Aanstoot HJ, Waarde WM, Houdijk EC, et al. Diabetes IN develOpment (DINO): the bio-psychosocial, family functioning and parental well-being of youth with type 1 diabetes: a longitudinal cohort study design. BMC Pediatr. 2015;15:82.

5. Ly T, Maahs DM, Rewers A, Dunger D, Oduwole A, Jones TW. Assessment and management of hypoglycemia in children and adolescents with diabetes. Pediatr Diabetes. 2014;15:180-92.

6. Kobuke K, Yoneda M, Nakanishi S, Ohno H, Maeda S, Egusa G. Efficacy and safety of insulin degludec in Japanese patients with type 1 and type 2 diabetes: 24-week results from the observational study in routine clinica practice. J Diabetes Investig. 2016;7:94-9.

7. Rewers MJ, Pillay $\mathrm{K}$, de Beaufort $\mathrm{C}$, Craig ME, Hanas R, Acerini $\mathrm{CL}$, et al. ISPAD Clinical Practice Consensus Guidelines 2014. Assessment and monitoring of glycemic control in children and adolescents with diabetes. Pediatr Diabetes. 2014;15 Suppl 20:102-14.

8. Jones TW, Davis EA. Hypoglycemia in children with type 1 diabetes: current issues and controversies. Pediatr Diabetes. 2003;4:143-50.
9. Danne T, Bangstad HJ, Deeb L, Jarosz-Chobot P, Mungaie L, Saboo B, et al. ISPAD Clinical Practice Consensus Guidelines 2014. Insulin treatment in children and adolescents with diabetes. Pediatr Diabetes. 2014;15 Suppl 20: 115-34.

10. McCall AL. Insulin therapy and hypoglycemia. Endocrinol Metab Clin N Am. 2012:41:57-87.

11. Raedler LA. Tresiba (insulin Degludec injection) and Ryzodeg 70/30 (insulin Degludec and insulin Aspart injection): two new insulin analogs for glycemic control in diabetes mellitus. Am Health Drug Benefits. 2016;9:144-8.

12. Mathieu C, Hollander P, Miranda-Palma B, et al. Efficacy and safety of insulin degludec in a flexible dosing regimen vs insulin glargine in patients with type1 diabetes (BEGIN: FlexT1): a 26-week randomized, treat-to-target trial with a 26-week extension. J Clin Endocrinol Metab. 2013;98:1154-62.

13. Heller S, Buse J, Fisher M, Garg S, Marre M, Merker L, et al. Insulin degludec, an ultra-longacting basal insulin, versus insulin glargine in basal-bolus treatment with mealtime insulin aspart in type 1 diabetes (BEGIN BasalBolus Type 1): a phase 3, randomised, open-label, treat-to-target noninferiority trial. Lancet. 2012;379:1489-97.

14. Kaku K, Eid MA. Safety, efficacy, and early clinical experience of insulin degludec in Japanese people with diabetes mellitus: a first-year report from Japan. J Diabetes Investig. 2015;6:610-9.

15. Predieri B; Bruzzi P; Maltoni G; Zucchini S, lughetti L. Efficacy and safety of insulin degludec in children and adolescents with type 1 diabetes. 42nd Annual Meeting of the International Society for Pediatric and Adolescent Diabetes (ISPAD) - Valencia, Spain - 26-29 October 2016) - PEDIATRIC DIABETES - n. volume 17 - pp. da 106 a 106. 2015

16. Thalange N, Deeb L, lotova V, Kawamura T, Klingensmith G, Philotheou A, et al. Insulin degludec in combination with bolus insulin aspart is safe and effective in children and adolescents with type 1 diabetes. Pediatr Diabetes. 2015;16:164-76.

17. Urakami T, Mine Y, Aoki M, Okuno M, Suzuki J. A randomized crossover study of the efficacy and safety of switching from insulin glargine to insulin degludec in children with type 1 diabetes. Endocr J. 2017;64:133-40.

18. Heise T, Hermanski L, Nosek L, Feldman A, Rasmussen S, Haahr H. Insulin degludec: four times lower pharmacodynamic variability than insulin glargine under steady-state conditions in type 1 diabetes. Diabetes Obes Metab. 2012:14:859-64.

19. Heise T, Norskov M, Nosek L, Kaplan K, Famulla S, Haahr HL. Insulin degludec: lower day-to-day and within-day variability in pharmacodynamic response compared with insulin glargine $300 \mathrm{U} / \mathrm{mL}$ in type 1 diabetes. Diabetes Obes Metab. 2017:19:1032-9.

Ready to submit your research? Choose BMC and benefit from

- fast, convenient online submission

- thorough peer review by experienced researchers in your field

- rapid publication on acceptance

- support for research data, including large and complex data types

- gold Open Access which fosters wider collaboration and increased citations

- maximum visibility for your research: over $100 \mathrm{M}$ website views per year

At $\mathrm{BMC}$, research is always in progress.

Learn more biomedcentral.com/submissions 